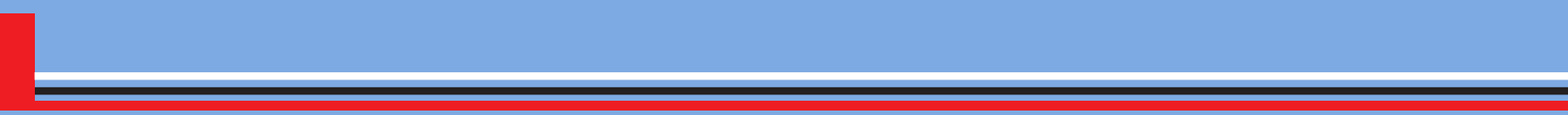




\section{€l paisaje como organizador territorial. Metodología y práctica: paisaje de minifundio de Boyacá ${ }^{1}$}

García, J. J. (2016). El paisaje como organizador territorial. Metodología y práctica: paisaje de minifundio de Boyacá. Designia, 4(1), 9-31

\section{territorial organizer. Methodology and practice: Boyacá's smallholding landscape}

\section{Palabras clave:}

\author{
Paisaje, ordenación territorial, \\ desarrollo sostenible, Boyacá, \\ minifundio.
}

Key words:

Landscape, territorial planning, sustainable development, Boyacá, smallholding

Recibido: 16-nov-2015 Aceptado: 19-sep- 2016

\footnotetext{
${ }^{1}$ Este artículo forma parte de la investigación Observatorio de los paisajes culturales de Boyacá, financiada por la Universidad Santo Tomás (Tunja) dentro de la línea "Memoria histórica arquitectónica y urbana" de su Facultad de Arquitectura.

* Licenciado en Geografía e Historia por la Universidad Complutense de Madrid, Máster en Patrimonio Natural y Cultural por la Universidad Internacional de Andalucía. Docente e investigador de la Facultad de Arquitectura, Universidad Santo Tomás (Tunja).master.jjgarcia@smail.com
}

\section{Resumen:}

El paisaje ha sido visto siempre como una cuestión meramente estética, para deleite de los sentidos, en la cual prima su belleza por encima de otras cualidades. Desde hace unas décadas, dicho paradigma ha cambiado y se le ha visto también como un elemento que amalgama un territorio, poseedor de utilidad para la ordenación territorial y el desarrollo sostenible. Diferentes experiencias basadas en otras tantas metodologías se han aplicado para ponerlo como centro de dicha planificación. Con el método británico del análisis del paisaje por medio del carácter de sus elementos (Landscape Assessment (haracter), se logra una visión totalizadora que interrelaciona los elementos humanos y naturales, así como los históricos (pasados y actuales) con una mirada prospectiva orientada al desarrollo territorial y social, la protección medioambiental y la apropiación patrimonial. Este artículo centra su análisis en el departamento de Boyacá desde esa mirada metodológica, diferenciando su territorio en asociaciones de paisajes. El más representativo de estos, por su extensión e implicación social, es el minifundio o agrícola de subsistencia. Se examinan sus características, la valoración de estas y las propuestas para una gestión que lleve al desarrollo sostenible de la región.

\section{Abstract:}

Landscape has been always seen as a merely aesthetic matter for delight of the senses in which beauty prevails over other qualities. Such a paradigm has changed since few decades ago. Thus, landscape is now also considered as an element that articulates a territory, having value for territorial planning and sustainable development. Different experiences based on distinct methodologies have been applied in putting landscape in the center of this planning. The Landscape Assessment Character, a British method consisting in analysing landscape through the character of its elements, provides a complete insight connecting human, natural, and historical (past and present) elements within a prospective perspective pointing to the territorial and social development, the environmental protection and the heritage appropriation. This paper focuses on the Boyacá province, examining types of landscapes existing in its territory from the above mentioned method. Due to its extension and social impact, the most representative type is the smallholding, which is devoted to subsistence agriculture. Its characteristics, valuation and proposals for management, thinking in the region's sustainable development, are analysed here. 


\section{En 2011, la Organización de las Naciones Unidas para la Educación, la Ciencia y la Cultura (Unesco) por medio de su Comité del Patrimonio Mundial, declaró más de 140.000 ha en la parte centro- occidental de Colombia como Paisaje Cultural de la Humanidad. Se trató del Paisaje Cultural Cafetero, cuya declaratoria lo consideró representativo en el mundo no solo por su forma visual de modelación del territorio asociada a dicho cultivo, en la cual los elementos naturales se modificaron en beneficio de los cafetales, sino también por sus formas de asentamiento humano, origen de estas, arquitectura, técnicas tradicionales de construcción en entornos urbanos y rurales, asociaciones, adaptaciones y agrupaciones sociales, económicas y culturales. Se destacó como la cultura cafetera se manifiesta en diferentes aspectos de la vida de la población.}

¿Cuál es la definición de Paisaje Cultural en que se basa la Unesco? En 1992, la organización definió un nuevo tipo de bien, una parte más o menos extensa del territorio, de naturaleza mixta y heterogénea. El Comité del Patrimonio Mundial los reconoció como bienes culturales que representan las obras conjuntas del hombre y la naturaleza, por lo tanto, ilustran la evolución de la sociedad humana y sus asentamientos a lo largo del tiempo. Son condicionados por las limitaciones y oportunidades físicas de su entorno natural, al igual que por las sucesivas fuerzas sociales, económicas y culturales, ya sean externas o internas. 
En esta definición se reconocen los valores relacionados con el término paisaje, tanto para las poblaciones humanas (con sus variables culturales) como para la diversidad natural, y en general para todo el universo de interacciones, aprovechamientos, adaptaciones y manifestaciones que impliquen la asociación de un territorio con un colectivo humano concreto y sus formas de vida. A pesar de este reconocimiento de 1992, fue hasta 2008 cuando por medio de las Directrices Operacionales de la Unesco el concepto se desarrolló, se definieron sus procedimientos y se establecieron tres categorías: paisaje cultural diseñado intencionadamente, orgánicamente evolutivo y asociativo.

El presente artículo no se centra en cómo los paisajes culturales son declarados Patrimonio Mundial, sino en identificar y establecer metodologías y técnicas para su diferenciación, conocimiento, preservación y divulgación. En una segunda parte, se expone de manera sucinta la aplicación de una de estas metodologías a un paisaje del departamento de Boyacá, en el centro-oriente de Colombia. Antes de entrar en el desarrollo metodológico, es conveniente conocer diferentes perspectivas y paradigmas en torno al concepto, cuando es considerado como un territorio.

\section{EL CONCEPTO DE PAISAJE}

El paisaje es una obra en común del ser humano y del medio natural, de ahí su variedad, desde los casi verdaderamente naturales a los completamente intervenidos por el hombre, en una secuencia lógica y evolutiva. Así, a lo largo de la evolución del término, sus características y criterios se han modificado.

El primero en establecer un estudio científico de carácter inductivo mediante el método empírico de observación sistemática del territorio fue Alexander Von Humboldt, con su Expedición Científica de 1799. Este científico y geógrafo reconoció una serie de unidades espaciales diferenciadas, aunque con normas genéticas similares. Para el explorador alemán, tales territorios poseían una fisonomía visible, pues los definió como áreas homogéneas del espacio donde se relacionan el medio natural con el ser humano, e incorporó además la percepción como parte fundamental para su reconocimiento.

En el siglo XX, la Escuela Alemana del Paisaje lo entendió como unidades del territorio y formuló una definición que fue mayoritaria y la más extendida por varias décadas: el Paisaje Cultural (Kulturladschaft) es el reconocimiento de la forma y disposición de los fenómenos de la superficie terrestre, en tanto estos son perceptibles por los sentidos. De forma similar, la Escuela Francesa de Vidal de 
la Blache estableció distintos territorios que equiparaba a regiones, cada una con un "sénero de vida" (Bertrand, 2010). Por su parte, la Ecología del Paisaje lo consideró un mosaico de ecosistemas, entidades naturales que evolucionan por causas naturales o antrópicas. González Bernáldez (1981) lo definió como una percepción multisensorial de un sistema de relaciones ecológicas, es decir, el conocimiento de los ecosistemas y sus diferentes grados de transformación.
Desde las Ciencias Sociales el paisaje deriva hacia postulados historicistas, al considerarse un hecho histórico y social. Un complemento al espacio y la sociedad histórica, una tercera vía a la hora de definirlo y sistematizarlo, es la percepción. Por medio de esta se le ve como una subjetividad humana, surgida de un análisis introspectivo del territorio por parte de la sociedad. En un salto cualitativo, al ser tal construcción es entonces una elaboración personal, social y simbólica. Se empieza así a elaborar estudios más antropológicos que le dan un significado cognitivo-subjetivo, y se comienza, sobre todo, a pensar en sus recursos identitarios.

\section{Contexto internacional del concepto}

Superada la visión meramente estética, desde fines del siglo XX las temáticas paisajísticas se abordaron mediante acuerdos, cartas, convenios o políticas nacionales o trasnacionales. Por su importancia internacional y su grado de consenso cabe destacar el Convenio Europeo del Paisaje (CEP) (Consejo de Europa, 2000), firmado en Florencia (Italia), que lo comprendió como cualquier parte del territorio percibida por la población, cuyo carácter es el resultado de la acción e interacción de factores naturales y humanos. La finalidad de este Convenio fue estimular la adopción de medidas para identificar, proteger, planificar y gestionar los paisajes de Europa como recursos para el fortalecimiento cultural y la identidad local, frente a la pérdida de la individualización y la uniformización existente en el mundo actual. Estas acciones buscaban, a su vez, generar una mejor calidad de vida en la población. Los puntos de atención fueron:

a) No adjetivar el paisaje. No se le tildó de natural, cultural o patrimonial, sino que todas sus formas, extraordinarias o comunes, merecieron protección y gestión.

b) Interrelacionar los componentes naturales, humanos y sus conexiones, pues son los que confieren diversidad y calidad.

c) El carácter, es decir, la suma e integración de las características humanas y físicas, no es solo una concatenación de elementos: es lo que individualiza y da valor desde una mirada histórica, actual y prospectiva. Este carácter quizás sea el elemento definitorio de la metodología al momento de la gestión. 
d) Incluir a las comunidades a través de su percepción. ¿De qué forma lo identifican quienes lo habitan, generan, construyen y asumen como propio? Es un concepto en dos direcciones que incorpora la retroalimentación entre una población y su territorio, entre sociedad y paisaje. De tal modo, este es también social y sensitivo.

Identifica el

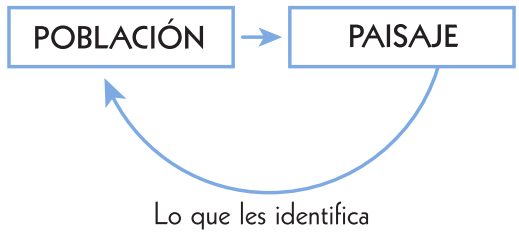

Gráfico 1. Relación entre población y paisaje. Fuente: autor.
Estos puntos permiten enumerar principios generales en torno al paisaje:

a) Considerar al territorio en su totalidad (espacios naturales, rurales, urbanos, periurbanos, terrestres, acuáticos, cotidianos, relevantes o degradados), más allá del bien patrimonial.

b) Reconocer el papel fundamental del conocimiento en sus tres fases de análisis: identificación, caracterización y cualificación (basadas en la metodología Landscape Assessment Character, LAC). Este conocimiento debe ser natural, cultural, histórico, morfológico, diacrónico y dinámico.

c) Considerar la percepción de la población en la apropiación de los paisajes como propios. Esto incluye sensibilización y acercamiento de conocimiento especializado.

d) Formular estrategias a escala local, regional y suprarregional, encaminadas a la gestión, protección y recuperación de los paisajes actuales y a la creación de otros.

e) Integrar el paisaje en las políticas sectoriales y de ordenación territorial.

\section{Marco conceptual del paisaje cultural}

La evolución reciente en la comprensión del paisaje ha marcado una rectificación sustancial de su contenido teórico y práctico. Se ha pasado de la visión naturalista de los años ochenta del siglo pasado a la perspectiva de los noventa en que todo se convirtió en protección, para llegar al momento actual de una vocación totalizadora.

En la tabla 1 se observan las diferencias en la concepción del paisaje.

\begin{tabular}{|c|c|}
\hline $\begin{array}{l}\text { VISIÓN } \\
\text { TRADICIONAL }\end{array}$ & VISIÓN ACTUAL \\
\hline Protección & Protección, Gestión y Ordenación \\
\hline Paisajes sobresalientes & $\begin{array}{l}\text { Visión totalizadora. El Paisaje es todo } \\
\text { el espacio }\end{array}$ \\
\hline Espacial & $\begin{array}{l}\text { Espacial y temporal (pasado, presente } \\
\text { y futuro) }\end{array}$ \\
\hline Estética (decorado) & $\begin{array}{l}\text { Solidaridad, bienestar, salud, } \\
\text { marco vital }\end{array}$ \\
\hline Visitar & Residir \\
\hline
\end{tabular}

Tabla 1. Diferenciación entre visión tradicional y actual del paisaje. Fuente: autor. 


\section{Con su concepción espacial y}

universal, la visión actual lleva a la dignificación de cualquier paisaje, a su intervención y a la formulación de objetivos futuros. Así, desde la base de este derecho y con visión prospectiva, es posible establecer acciones prioritarias para preservar o mejorar su calidad y expandir por ende el bienestar a la sociedad. Se le entiende entonces como un marco de unión y coherencia entre las políticas sectoriales y los intereses particulares y generales, un reflejo social, donde los abusos de particulares o la negación del Estado se hacen patentes. Cuando es bien concebido y armónico significa un factor de convivencia frente a los conflictos. Asimismo, representa al medio ambiente, la sociedad, las formas, los procesos, la construcción física y la representación psicológica.

Diferentes metodologías, tendencias y orientaciones se han ocupado de su análisis, de acuerdo con las concepciones de cada una, en relación con sus finalidades y objetos de estudio. Además de la Ecología del Paisaje, cabe destacar la ya mencionada Escuela Alemana, la Soviética del Geosistema, la Francesa de Besançon, el modelo italiano del paisaje de contenido histórico y el LAC británico como las escuelas metodológicas que más profundamente y con un enfoque prospectivo han trabajado en este campo.

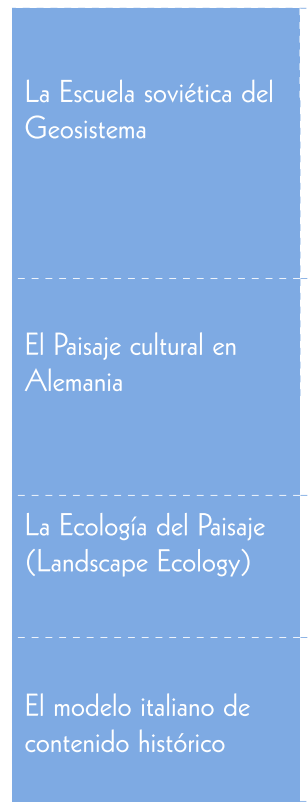

Asociada a la antigua Unión Soviética. Su desarrollo y conceptualización se realizó durante el periodo soviético. Con su filosofía práctica, utilitaria y materialista buscó identificar los recursos existentes en su territorio y aprovecharlos al máximo.

El paisaje, complejo conformado por componentes naturales y geográficos, fue denominado con el término "Geosistema", un neologismo por aquel entonces.

El paisaje cultural, generado por la acción sostenida, el uso residencial y productivo de un paisaje natural, se identifica con patrimonio. Tal acción es ejercida por sociedades humanas y genera marcas que definen diferenciaciones regionales no motivadas por la naturaleza. Claro está que la influencia de esta es mayor en cuanto más débil es el componente tecnológico

Su objeto de estudio se centra en las relaciones entre los procesos ecológicos (interacciones de los seres vivos con su entorno) y la organización del espacio. En sus trabajos prima la atención a la escala territorial.

El paisaje es fundamentalmente histórico. Sus valores estéticos de contemplación y de lectura se deben a la historia. Esta expresa el sentido de cada lugar, desde los cambios sociales y económicos en la visión del mundo.

Tabla 2. Escuelas y métodos de trabajo con el paisaje. Fuente: autor.

\section{METODOLOGÍA}

Una vez revisada la variedad de métodos para el análisis científico del paisaje, el trabajo investigativo optó por una metodología flexible, ampliamente trabajada en Europa y que por su adaptabilidad es válida para cualquier rincón del planeta. Su visión es práctica, de futuro e integradora, pues recoge la evolución histórica de los paisajes y se centra en el estudio del territorio y la sociedad. 
Se trata del LAC o carácter del paisaje. De encuadre perceptivo y muy difundida en las Islas Británicas, se basa en el esquema simple de gente y lugar (people and place). En este enfoque, el paisaje pasa de ser un bien patrimonial y se comprende como un recurso para la actividad económica y social, al igual que para el bienestar individual basado en el desarrollo sostenible. En tal concepto sentó sus bases el CEP con las características ya señaladas (el territorio visto en su conjunto, como un recurso, en continua contribución a la identidad y especificidad de una población, en el que la percepción, las emociones y el reconocimiento hacia tal entorno, hacia su particularidad histórica y cultural son esenciales).

La participación de la población en la toma de decisiones y su intervención en la protección, gestión y ordenación es fundamental. Estos procesos se definen así: a) Protección: acciones encaminadas a conservar y mantener los aspectos significativos o característicos de un paisaje, justificados por su valor patrimonial. b) Gestión: medidas destinadas a garantizar su mantenimiento regular en aras de armonizar la transformación producida por dinámicas sociales, económicas y medioambientales. Se debe conseguir una evolución armónica.

c) Ordenación o diseño: acciones prospectivas que apuntan a mejorar, restaurar o crear paisajes. Aquí se incluye la remodelación paisajística, pues al rehabilitar o proyectar se busca satisfacer las demandas y aspiraciones de los interesados.

En el método $L A C$ se distinguen tres fases:

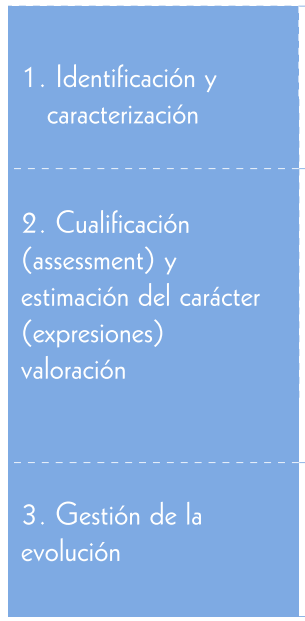

Descripción y clasificación

Denominación de las unidades (áreas) y agrupaciones (tipos) de paisajes Se valora la singularidad de los paisajes

Herramientas: utilización de métodos telemáticos y del trabajo de campo Se valoran los atributos de cada paisaje

Se estima el valor y la significación

Se toma el conjunto de atributos de manera global para definir su carácter, mediante consenso social

Se establecen las acciones que es preciso emprender con relación a cada paisaje y el peso de cada una de estas (protección, gestión, ordenación) El carácter es el resultado de un conjunto de rasgos fisionómicos, diferenciables y reconocibles.

Las medidas establecidas van desde la protección estricta para la conservación de los paisajes actuales a la creación de nuevos paisajes gravemente dañados.

Se debe reconocer la diversidad de los paisajes heredados.

Tabla 3. Fases del método (LAC).

Fuente: autor.

Con base en esta metodología se presenta a continuación el estudio de un paisaje boyacense. ¿Por qué se eligió el LAC, que ha sido implantado en Europa y no en el ámbito latinoamericano? Por varios motivos:

1. El objeto de estudio es el paisaje, cuyo único adjetivo es "boyacense". Este 
cubre la totalidad del territorio, es sustantivo y se vale por sí solo. Como expresa Mata Olmo (2008), es el resultado de la relación sensible de las personas con su entorno percibido, cotidiano o visitado. Es un elemento de identidad territorial, manifestación de una diversidad del espacio geográfico que se hace explícita en la propia materialidad y en sus representaciones sociales.

2. Porque paisaje es cualquier parte del territorio, sin límites ni barreras, entendido como marco de vida y escenario de un grupo social. Esto implica que su estudio y gestión no se limita a lo sobresaliente, a la "postal" ○ "el afiche", sino a toda la superficie. Al tratar igual el paisaje excepcional y el cotidiano, el concepto incide en el diagnóstico de procesos a veces insostenibles y acelerados de consumo de suelo.

3. En el campo psicológico y subjetivo, la percepción lleva a compromisos no visibles pero plasmados sobre la territorialidad. Por ello, las sociedades son a la vez objetos y protagonistas, por su participación y apropiación del territorio.
4. El carácter del paisaje es resultado de la interacción entre factores naturales y humanos. Estos imprimen una forma, una peculiar estructura organizativa, una huella llamada sociedad, forjada a lo largo de la historia sobre un medio específico. Así, un entorno es a la vez histórico, ambiental, sistémico y funcional. Es un palimpsesto, un organismo en evolución con sus dinámicas y flujos.

5. Tal condición le confiere un sentido patrimonial, adjetivo que puede entenderse como recurso, ya sea para la identidad local o regional, para la economía al ser un creador de empleos y para el desarrollo sostenible.

Esta metodología cubre la totalidad del territorio y lleva a su anidamiento escalar, para propiciar así diferentes acercamientos según sea la finalidad del análisis. En el estudio aquí presentado, con tal anidamiento o fractalidad, los paisajes quedan identificados de este modo:

Asociación de tipos: paisaje de microfundio.

Tipos: microfundio de páramo, de altiplanos y valles templados, de ladera, de piso térmico cálido.

Áreas: microfundio del entorno urbano de Tunja, de los valles de Pómeca, de Tenza, y del río Suárez.

La valoración de los atributos del paisaje y de su capacidad para acoger, absorber e integrar cambios, revela su grado de calidad y sus posibilidades para satisfacer las necesidades de la sociedad. Estos objetivos de calidad se plasman en indicadores y otorgan una visión real que ha de conducir a la fase propositiva. El diagnóstico debe hacerse en las tres escalas previamente referidas. En esta fase se habla de capacidad y sensibilidad. Lo primero expresa en qué medida el paisaje puede acoger cambios o efectos negativos. Lo segundo señala su probabilidad de vulnerabilidad o pérdida de carácter.

En la valoración es necesario conocer la integridad, la fragilidad y las tendencias de los atributos descritos. Estas últimas se identifican por métodos inductivos y a través de participación pública (paneles con expertos y con población local), con el fin de conocer las actividades que generan presión para el paisaje, las cuales, en 
mayor o menor medida, se agrupan en: de base agraria y ganadera, forestal, extractiva, urbanización, grandes infraestructuras y redes energéticas.

Por último, en la gestión se establecen las líneas de actuación tras establecer los objetivos de calidad. Si bien estas líneas se encuentran bien definidas, la toma de decisiones varía según sea el grado de calidad, alteración, conservación o adaptación de cada entorno. Por lo tanto, la atención puede centrarse en la protección, gestión, recuperación o creación.

\section{RESULTADOS}

El estudio aquí presentado, extraído del proyecto Observatorio de Paisajes de Boyacá, analiza el conjunto del territorio departamental. Con la metodología descrita se definieron grandes asociaciones de tipos, debido a la amplitud espacial. Entre estas se examina en profundidad el paisaje de agricultura de subsistencia o de minifundio y concretamente dos espacios: el área rural del municipio de Ventaquemada y el área metropolitana rural de Tunja, centrada en los pueblos de Chivatá, Soracá, Motavita y Cómbita, donde la ruralidad es distorsionada por las influencias sociales, económicas, de forma y de economía establecidas por Tunja, la ciudad capital. Tras una fase inductiva de trabajo de campo, el Observatorio identificó seis grandes asociaciones de paisajes: paramuno, colonial, urbano-industrial, minero, simbólico, de agricultura de subsistencia o minifundio.

Antes de examinar este último es pertinente realizar una aproximación a Boyacá, donde es predominante. Dicho departamento, asentado en la Cordillera Oriental de los Andes colombianos, en el centro-oriente del país, posee un carácter principalmente montañoso, si bien hacia el oriente se abre a los Llanos Orientales y hacia el occidente al valle medio del río Magdalena. Son casi $24.000 \mathrm{~km} 2$ elevados, con una altitud media alrededor de los $2500 \mathrm{~m}$, dominados por las altas parameras que culminan al norte en el macizo nevado del Cocuy, donde dos ríos, el Suárez y su tributario el Chicamocha, se abren paso segmentando la cordillera.

Prevalece el piso térmico frío, en el cual se asienta la mayoría de la población. El valle de Tunja y la conurbación Sogamoso-Duitama son las dos entidades urbanas de importancia. El resto del territorio es rural, con más de 120 municipios repartidos en cabeceras y veredas de poblamiento disperso, situación favorecida por el relieve. 
La falta de oportunidades, el abandono por parte de las administraciones públicas, el atraso en infraestructuras y dotaciones, motivan una fuerte emigración de la zona rural a las ciudades del departamento, o bien hacia Bogotá o Bucaramanga. El 36\% de la población vive en situación de pobreza extrema (Figura 2). La economía se basa en la construcción, los servicios en las ciudades, la industria en áreas concretas, la minería y la economía agraria. En esta tesitura se mueve el territorio rural boyacense, caracterizado por el paisaje de minifundio de subsistencia.

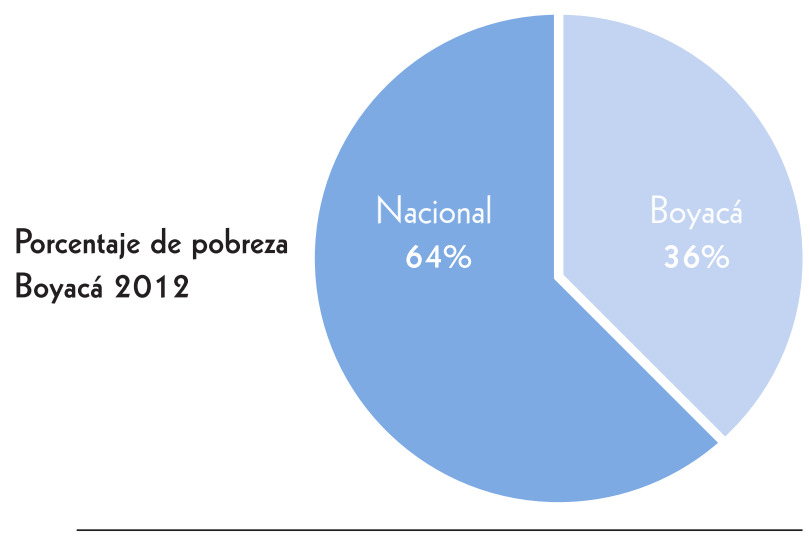

Gráfico 2. Porcentaje de pobreza en Boyacá. Fuente: Obtenido del Boletín de Pobreza 2014 del Observatorio Social Tierra Viva.

\section{Caracterización del paisaje minifundio o de agricultura de subsistencia}

Se relaciona con la vida bucólica, campesina, de producción agroganadera de subsistencia, con un poblamiento disperso y en acelerado proceso de transformación. En otros lugares e idiomas se denomina de distintas formas: cultura promiscua, mixed farming, paisaje patchwork o de parches (debido a como se percibe en imágenes aéreas). Es el más fácilmente identificable en Boyacá y se repite en otros puntos del planeta. Puede considerarse un patrimonio rural y un factor clave para el futuro desarrollo territorial.

¿Por qué es patrimonial? Primero, porque es histórico y tradicional, es imagen e identidad de una sociedad, es un género de vida de una población. Su característica principal es el poblamiento disperso: un mar de diminutas parcelas vastamente extendidas que generan un sistema económico no competitivo, únicamente apto para suplir necesidades locales. Otro rasgo es su pequeña propiedad con atomización de la producción, sin asistencia técnica ni transferencia tecnológica.

Según los censos del Ministerio de Agricultura y Desarrollo Rural de Colombia (2005), las áreas de minifundio son las que agrupan predios inferiores a una Unidad Agrícola Familiar (UAF). Por debajo de media UAF se considera microfundio. Aunque pueden parecer parcelas grandes, es preciso tener en cuenta su nivel 
Se aprecia que Boyacá tiene casi un quinto de los minifundios en el país y un 5\%

del área nacional de estos predios, lo cual indica su acentuación microfundista.

tecnológico, cooperativo, de capitalización y accesibilidad. No es lo mismo el minifundio altamente capitalizado y comercializado de Antioquia o del Eje Cafetero, con un alto valor añadido, que el de la zona cebollera o papera boyacense. Boyacá es una de las regiones de mayor concentración de minifundio y microfundio en el país, según se aprecia en el siguiente mapa de la región andina colombiana.

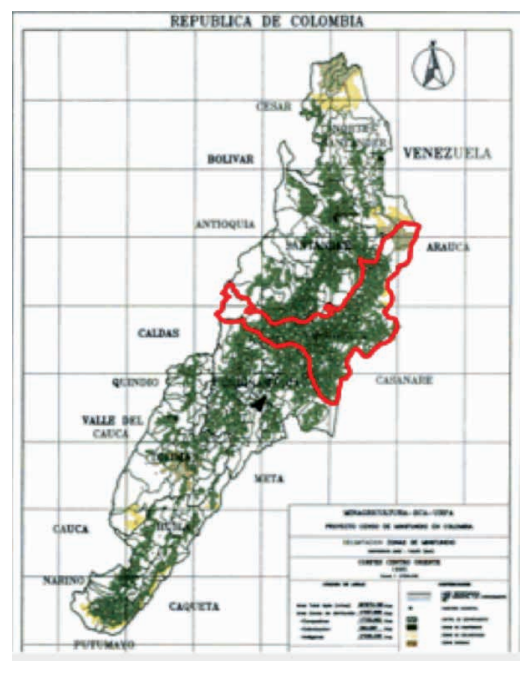

Figura 1. Mapa del Minifundio en la zona andina. Se destaca en rojo la geografía de Boyacá. Fuente: Elaboración propia y Censo de minifundio de Colombia

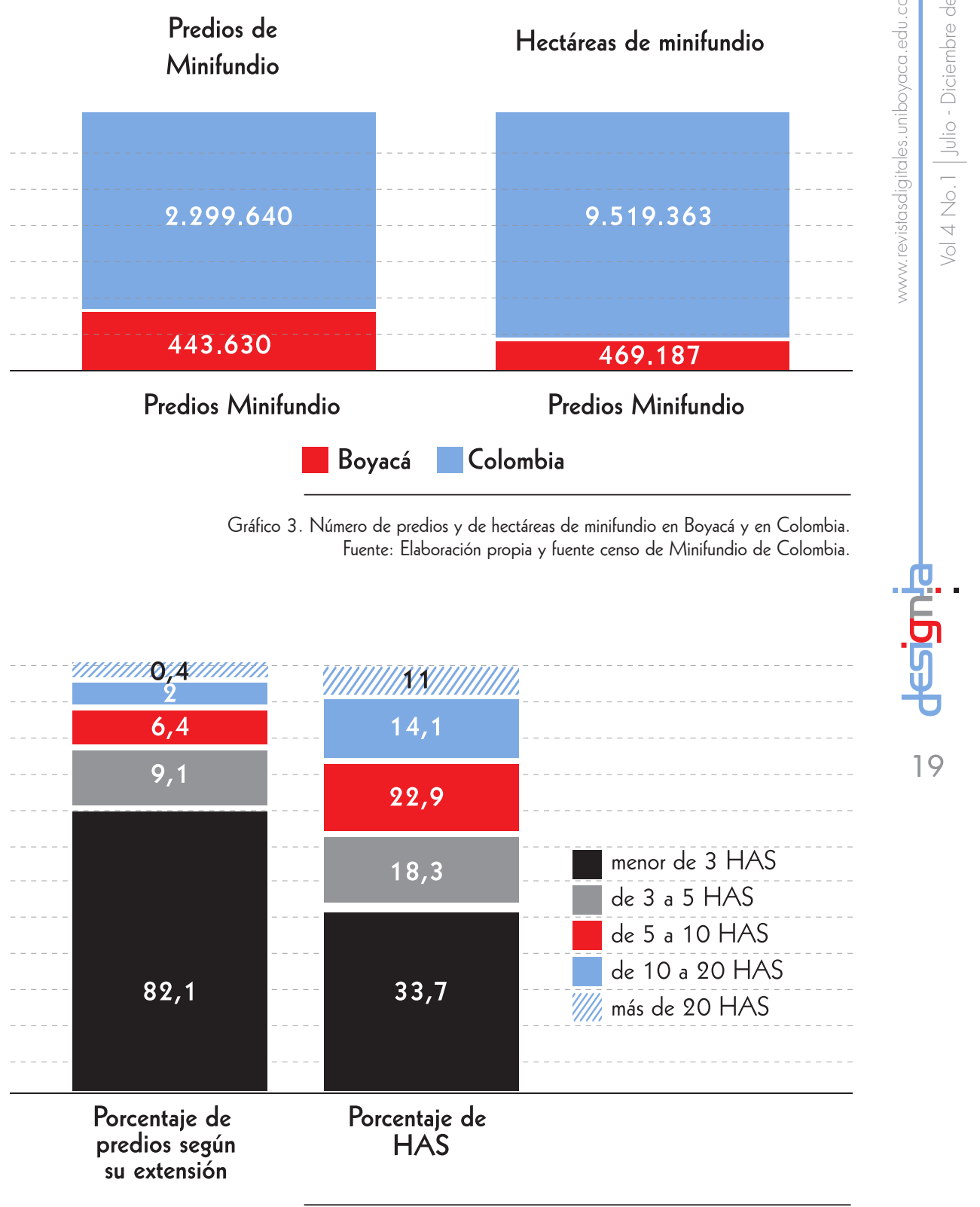

Gráfico 4. Predios en Boyacá según su extensión (en porcentaje) Fuente: Elaboración propia y fuente censo de Minifundio de Colombia. 
últimos fueron asignados a los indígenas por la Corona. Su propiedad era comunitaria, no se podían vender ni arrendar y tenían tres categorías: tierras comunales de bosque y pastoreo, las dedicadas al pago del tributo y sostenimiento del cura doctrinero, y los lotes de usufructo familiar (Vélez Álvarez, 2012).

Los resguardos se crearon hacia 1600 para proteger a los indígenas, como vasallos libres del rey, de la explotación de encomenderos y colonos. A partir de 1750, los conflictos por la disminución de población nativa y el aumento de blancos pobres y mestizos motivaron la liquidación y el remate de buena parte de estas tierras. Entre 1755 y 1778, en la provincia de Tunja hubo 39 resguardos disueltos que afectaron a 29.000 personas (Melo, 2007). La consecuencia de tal disolución fue la generación de un acusado minifundio, originado por las Leyes de Indias y reafirmado por la repartición en herencia entre los hijos varones, en vez de ejercer la práctica del mayorazgo. Ya en época republicana, con el Decreto del 20 de mayo de 1820, Simón Bolívar cedió de pleno derecho los aún existentes a los indígenas, medida ratificada en el Congreso de Cúcuta del año siguiente por la Ley 11 de octubre de 1821, la cual iba acompañada por la prohibición de vender las tierras hasta 40 años después (Vélez Álvarez, 2012). Así se llegó a la constelación de minifundios y microfundios extendidos por la zona rural de Boyacá y gran parte del país.

El valor histórico del minifundio, por el cual también se le considera patrimonial, se encuentra en ser una forma heredada de tenencia de la tierra. Su origen se remonta a los repartos de tierras en la Colonia. Tras la Conquista española, estas se dividieron en haciendas, de la Islesia, baldías o de dominio público y resguardos. Estos

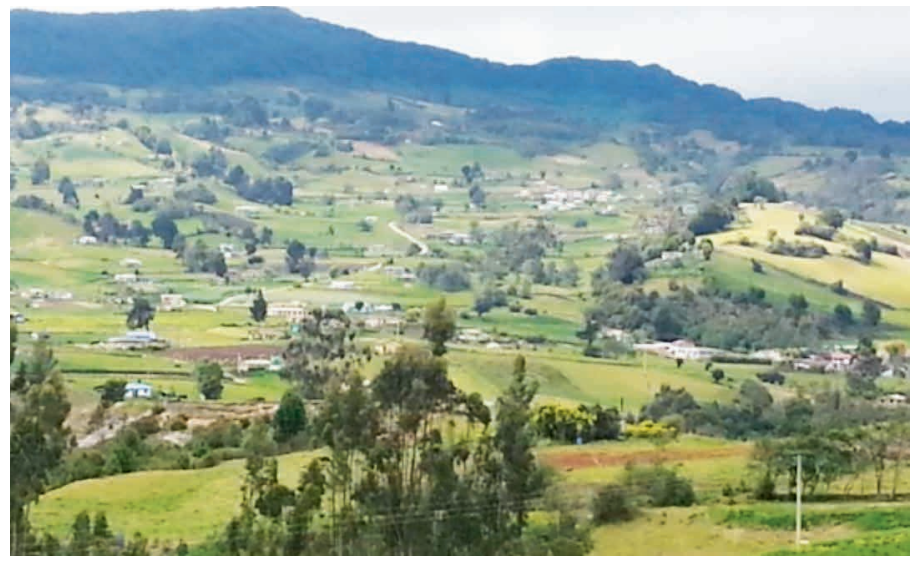


Estas unidades poseen atributos y características que los adjetivan más allá del tamaño de la propiedad.

Cada parcela se compone de: linderos, zonas de cultivos, de "jardín criollo" y de habitación. A continuación se describen estos elementos.

Linderos. Las parcelas han sido siempre limitadas por elementos naturales o por construcciones antrópicas. Los primeros son hileras de árboles paravientos, que junto a su función de barrera y aviso de límite, permiten nitrificar la tierra, frenan y retardan la llegada de la lluvia al suelo, generan pasto, son reserva ecológica y fuente de sombra, forraje y madera. De esta se elaboran los productos artesanales tradicionales del campesino (Pardo de Santayana y Gómez, 2003). Las construcciones suelen ser muros de tapia pisada, por lo general desmoronados, abandonados y sustituidos por alambres de espino y estacas de madera.

Cultivos. Los tradicionales han sido aquellos requeridos por el núcleo familiar para cubrir sus necesidades básicas y disponer de una reserva de alimentos a lo largo del año. Son un patrimonio mestizo, herencia indígena e influencia española, en razón de las especies cultivadas, la rotación y las técnicas agrícolas. Aún existe la estrategia prehispánica de la verticalidad mixta (Castellanos Camacho, 2011). Los muiscas dominaron el territorio cundiboyacense hasta la llegada de los españoles gracias a su estructura jerárquica social y al dominio agrotecnológico de pisos térmicos variados, condiciones que les permitieron tener alimentos y excedentes durante todo el año, los cuales comerciaban con pueblos vecinos.

En la parcela actual se registra simultáneamente una producción de distintas naturalezas. Se trata de una cultura intercalar y cubre suelo (Luginbuhl, 1991). Son prácticas culturales y técnicas de un sistema agrológico patrimonial que aprovecha el agua de lluvia, la luz y el calor. Cultivar más de una especie, ya sea al mismo tiempo y de forma mixta (por ejemplo leguminosa y papa) o en diferentes momentos (maíz y papa), permite aprovechar la nitrificación de la tierra realizada por las especies. Esto reduce el uso de agroquímicos, ayuda a cubrir el suelo y a evitar tanto la erosión como la resequedad de la tierra causada por el intenso sol del altiplano. Así se maximiza el rendimiento requerido para la subsistencia familiar.

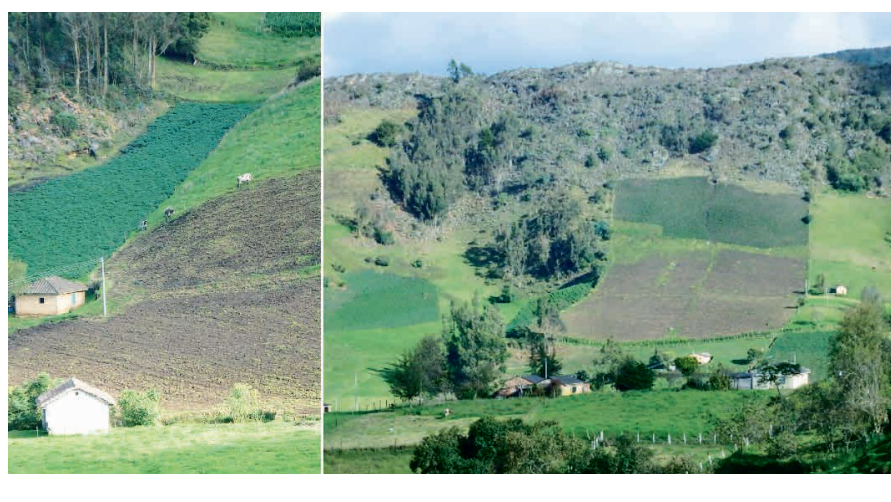

Figura 3. Parcelario y formas de cultivo en Ventaquemada, Boyacá. Fuente: autor. 
Los más extendidos son el maíz y la papa, base tradicional del alimento campesino y de la dieta balanceada prehispánica, a los que se añaden leguminosas, hortalizas y cereales (arvejas, tomates, plantas forrajeras, fríjoles) fruto de ese sincretismo agroecológico de los campos boyacenses. En áreas cálidas se cambia por caña panelera, yuca y especies más térmicas de frutales (naranjos, mandarinos, bananos, papayas, tabaco, curuba, café, madroños).

Estos cultivos para autoabastecimiento y producción de un pequeño excedente que se comercializa en los mercados locales, han venido siendo sustituidos por la papa y la cebolla, dos monocultivos para la venta. Estos no son comercializados por los agricultores sino por intermediarios, quienes imponen sus propios términos y se aprovechan de la poca capacidad de asociación del campesinado, así como de los vaivenes de los precios en el mercado. A su vez, la búsqueda de la máxima productividad conlleva al uso de fertilizantes artificiales y pesticidas, algunos incluso retirados de los mercados internacionales, que al entrar en la cadena alimenticia local ocasionan un envenenamiento lento en el suelo y en la población. Además, rompen la cadena orgánica tradicional y el equilibrio ecocultural.

Junto a esta agricultura, la cría de ganado para autoconsumo en cada unidad económica familiar también es representativa. Es posible encontrar vacas (para producción de leche), gallinas, pollos y más aleatoriamente, ovejas, cabras y cerdos.

Jardín criollo. Si los cultivos son un patrimonio cultural mestizo, en los jardines cercanos a la vivienda el patrimonio etnobotánico logra su mayor desarrollo. La denominación "jardín criollo" o jardin de case, está arraigada en toda la zona costera e insular del Caribe colombiano, asociada a un clima tropical cálido. El adjetivo "criollo" se ha mantenido por sus reminiscencias mixtas. Se trata del conjunto de plantas medicinales, aromáticas, ornamentales, culinarias, frutales y de otra índole que rodean los espacios habitacionales para formar espesos bosques en miniatura, donde se mezclan flores, hierbas, árboles y arbustos.

Sus especies son diversas, varían según el piso térmico y poseen múltiples usos: culinarios, medicinales, de barrera y defensa, bioclimáticos (sombra), ecológicos (nicho de anfibios, reptiles, avifauna y especies promisorias que ayudan a la nitrificación). Entre estas se identifican: buganvillas, heliconias, cayenas, borracheros y cartuchos (ornamentales); citrón, albahaca, cilantro, perejil, yerbabuena, poleo, limonaria, sauco, romero (gastromedicinales); naranjas, curubas, tomate de árbol, moras, toronjil, fresas, duraznos, bananeras (frutales); al igual que otras más como fique, tuno blanco, mortiño y alamandas. 


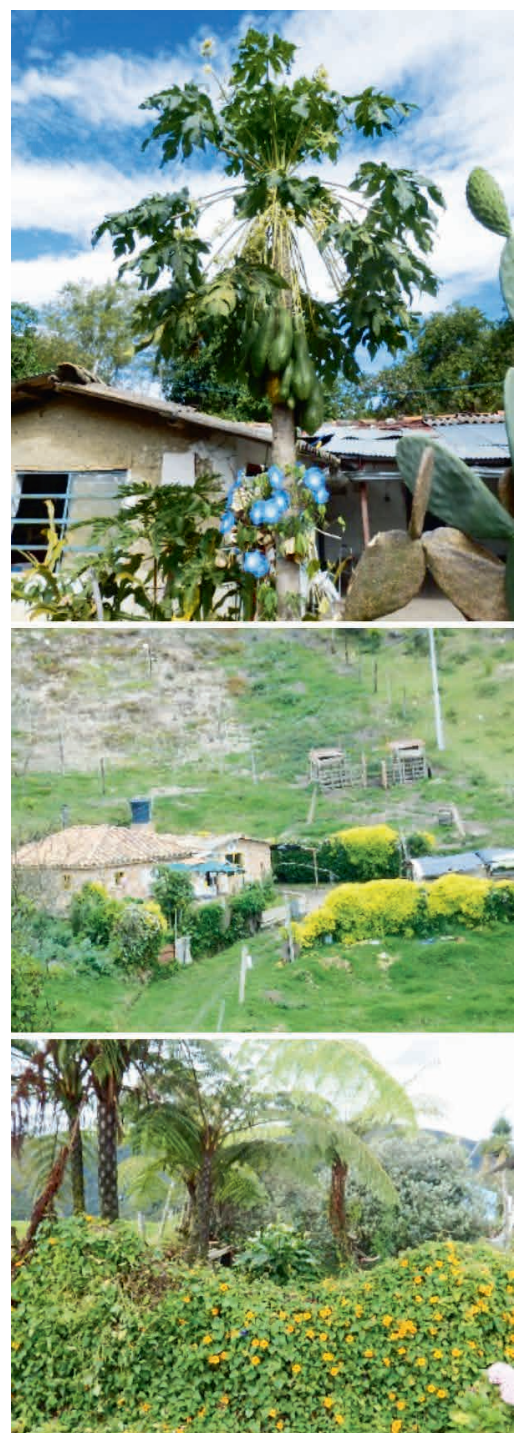

Figura 4. Ejemplos de Jardín Criollo (Boavita, piso térmico cálido) y Cómbita (piso térmico frío). Fuente: fotografía del autor.

Vivienda campesina. La vivienda rural tradicional es ecológica, adaptada al entorno y edificada con recursos del lugar. Su material fundamental es el adobe (barro secado), su planta y alzado se adaptan a la topografía ondulada y a los reservorios de agua. Es una pequeña fábrica de producción, unidad cultural y familiar cuando en ella se unifican el trabajo y las actividades derivadas de este (Orozco Farfán y Rojas Otero, 2000). El núcleo familiar, las asociaciones con el medio y con familias cercanas le dan esa unidad. Es un patrimonio construido e inmaterial en que se conjugan relaciones y expresiones socioculturales, creencias y usos. Como la parte más visible del constructo social del espacio, sirve de alojamiento familiar, habitación, lugar para la preparación de alimentos y el trabajo. Dentro de este último rol, puede albergar actividad artesanal si hay un procesamiento de productos rurales (secado de café o tabaco, desgrane de maíz, elaboración de panela).

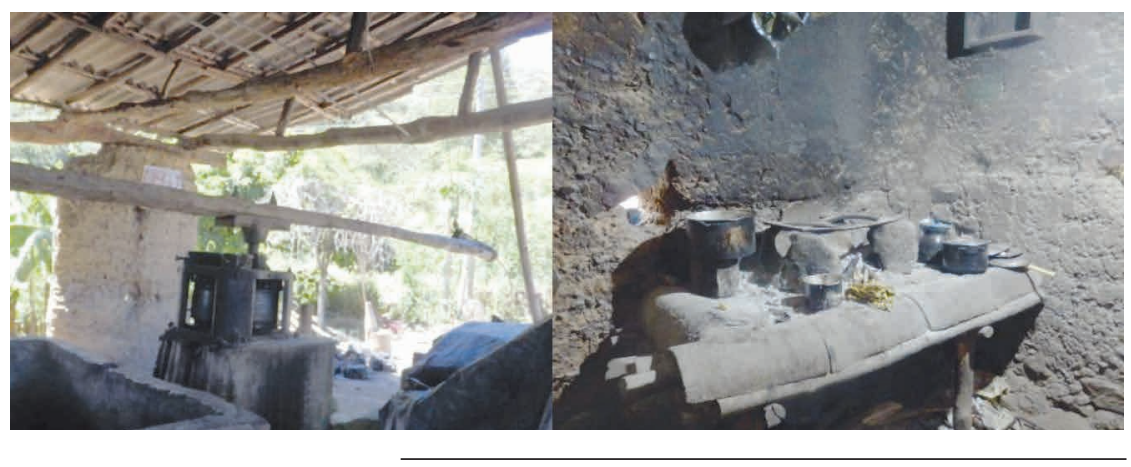

Figura 5. Trapiche de panela y cocina tradicional (Boavita) Fuente: autor.

Por sus materiales, aspecto y usos, es reflejo del mestizaje cultural: tradición muisca e influencia española (Saldarriaga, 2009). En esta arquitectura vernácula sincrética, la tradición prehispánica se refleja en el adobe, la tapia pisada, el bahareque o bien un uso alternado mixto con verdugadas. La vivienda tipo es un galpón de corredor interior central que distribuye espacios a lado y lado. La forma básica es el rectángulo, con tejado a dos aguas (en zonas cálida la cubierta es a cuatro aguas), y ausencia de vanos. Tal tipología varía, desde el rectángulo hasta las de forma en "L" y algunas 

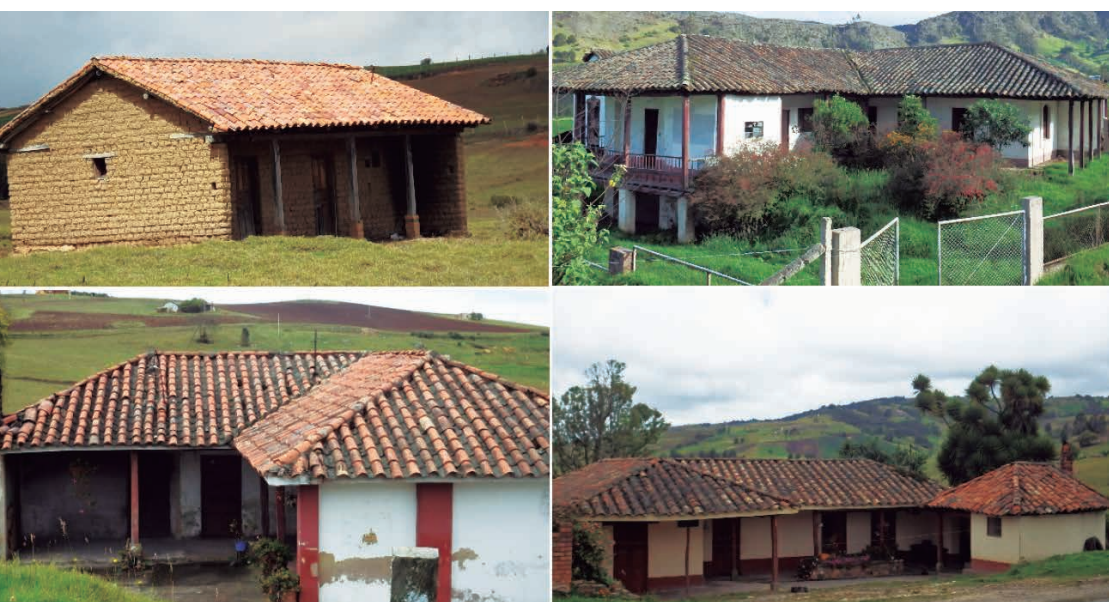

Figura 6. Viviendas de diferentes partes de Boyacá: Albarracín, Chivatá, Oicatá, Arcabuco. Fuente: autor.

Esta vivienda es sismorresistente, pues el adobe es elástico y al combinarse con hierbas alarga su elasticidad y evita el agrietamiento. Además, no emplea tímpanos triangulares que podrían colapsar. También es termoestable, debido a la cualidad aislante de los muros. Presenta una continuidad de elementos de mampostería, desde la cimentación hasta la cubierta. El tejado es de madera o chusque (bambú andino), con teja de barro española y alero hacia donde proviene la lluvia. Pero sobre todo, es barata, dado su bajo coste de materiales y poco consumo energético.

más amplias en "U". La entrada principal se encuentra en relación con el sendero de acceso, pero la apertura de espacios es hacia el valle. La decoración se basa en la pintura exterior, con un encalado o pañetado en cal y arena para protección del adobe, y ocasionalmente, zócalos dibujados y "dientes de perro" (decoración en el muro en forma de triángulos invertidos bajo el tejado).

\section{Fase valorativa o de diagnóstico del paisaje de minifundio boyacense}

Tras caracterizar los atributos que identifican al minifundio, la siguiente fase es valorarlos, saber cuál es su estado de integridad, de resilencia, su posibilidad de cambio o de adaptación, su grado de alteración, sus dinámicas y funciones. En general, el cambio en este paisaje es motivado por procesos globales que afectan al territorio de Boyacá. Uno de los más notorios es la emigración general en todas las zonas rurales, en especial por parte de la población joven, lo cual genera que numerosos campesinos se trasladen a ciudades cercanas, a Bogotá, Bucaramanga e incluso al extranjero. Asimismo, la búsqueda de mejoras económicas motiva una agricultura a tiempo parcial, pues esta se combina con actividades como la construcción o las labores domésticas por fuera del núcleo familiar. A su vez, el 
estilo de vida del mundo rural ha cambiado, influido por la globalización y la penetración de costumbres y prácticas urbanas, como también por el comercio de productos de otras latitudes, menos artesanales pero más fáciles de conseguir.

El siguiente es el estudio analítico por separado de cada elemento de este paisaje.

\section{Linderos. Los tradicionales han} desaparecido. No quedan límites de tapia pisada, solo las raíces de estas bardas, diseminadas por el campo, aparecen como reflejos de otros tiempos. Los árboles paravientos protectores se siguen manteniendo aunque de forma esporádica y las especies autóctonas han sido reemplazadas por otras de rápido crecimiento, como el eucalipto o el pino ciprés, que no son de la región. $\mathrm{Al}$ reducirse la barrera protectora se acaba con una fuente de materia prima artesanal, pérdida material e inmaterial causante de erosión cultural. Igualmente, al no frenarse el viento, se genera un efecto desecante y un desbalance climático.
Los límites de las parcelas son ahora de cercas de alambre y estacas de madera, muy alejados de las formas ecológicas tradicionales. Esto ha llevado a la tala de árboles, al uso de materiales contaminantes y a un cambio en la perspectiva global del paisaje, que de campo cerrado (bocage) ha pasado a campo abierto (openfield). La barrera se torna así en un efecto de agresividad social.

Jardín criollo. Se mantiene en la mayoría de predios. Tal pervivencia se debe a que cumple varias funciones: alimenticia (ayuda a complementar la dieta del campesinado), ambiental (patrimonio etnobotánico y biodiverso), medicinal, de mantenimiento de tradiciones ancestrales y saber popular, y de barrera protectora. Además, posee valores estéticos por la variedad y el colorido de frutales y flores.

Parcelario y técnicas de cultivo. En la actualidad, el autoconsumo propio del minifundio y el microfundio resulta inoperante e insuficiente, pues cuando no hay comercialización de productos no se aumenta la renta campesina. En algunas zonas subsisten los suelos cubiertos por cultivos intercalados. No obstante, los monocultivos eliminan los productos de pancoger. De igual modo, se aprecian técnicas y especies degradantes del suelo, erosión, uso de fungicidas, pérdida de la diversidad etnobotánica, abandono de tierras, desarraigo de las nuevas generaciones y olvido de técnicas ancestrales. En términos paisajísticos, se produce una acelerada homogeneización del paisaje.

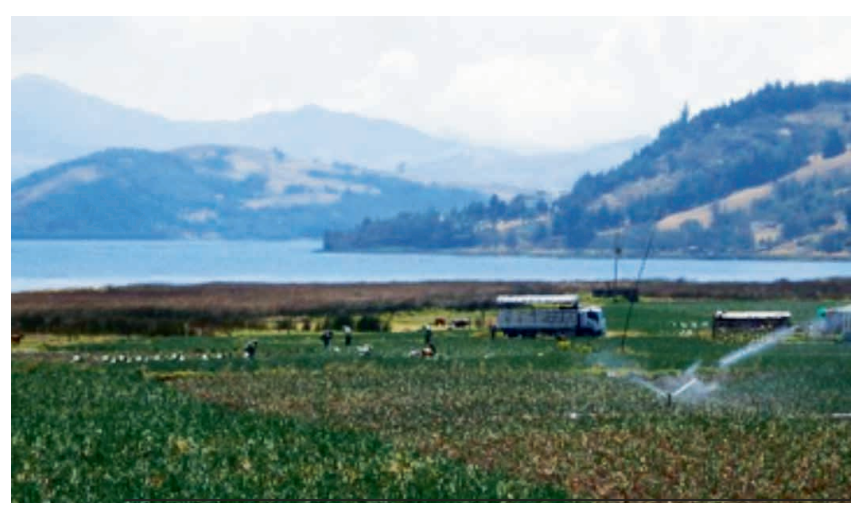

Flgura 7. Monocultivo de cebolla en el Lago de Tota (Boyacá). Fuente: autor. 
Vivienda campesina. Es quizás el elemento en que más se perciben modificaciones y alteraciones. Ante la emigración o la introducción de otras técnicas constructivas, la vivienda tradicional campesina ha sido abandonada. Esto ha significado su deterioro y hundimiento. Se observan nuevos modelos inapropiados para el entorno, más agresivos estéticamente y que no utilizan los sistemas y recursos tradicionales. Aparecen estéticas "sospechosas", con materiales erráticos y estilos poco acordes a la vida del campo. Además, no hay rehabilitación de esta vivienda, ya sea por el abandono o por los altos costos que esto implica. No solo se pierde el patrimonio construido, sino también oficios ancestrales, la artesanía y la adaptación al medio.

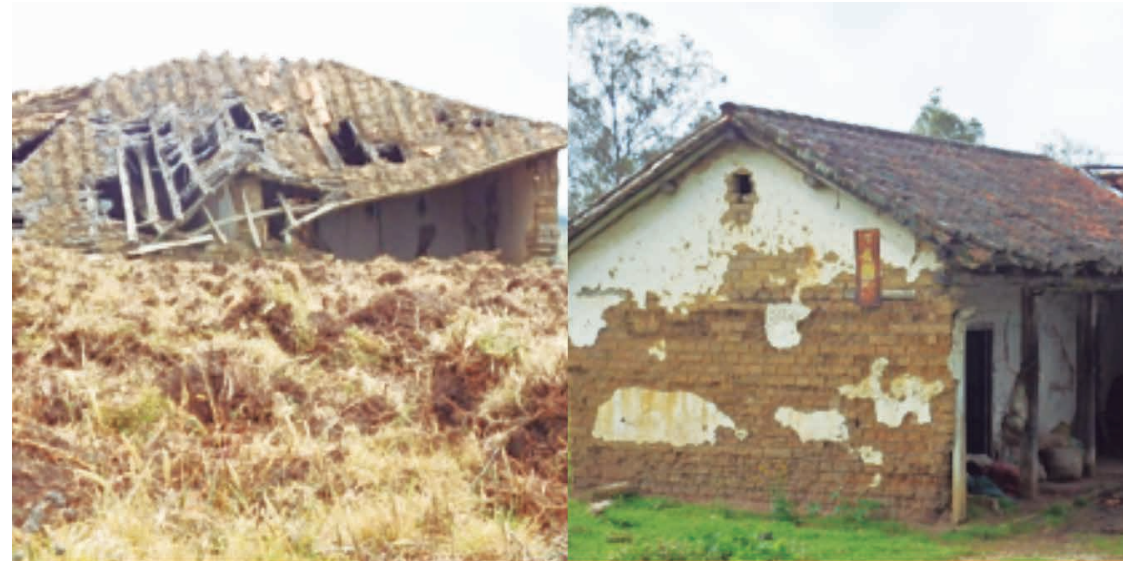

Figura 8. Pérdida y deterioro de la arquitectura vernácula. Combita y Chivatá. Fuente: autor.

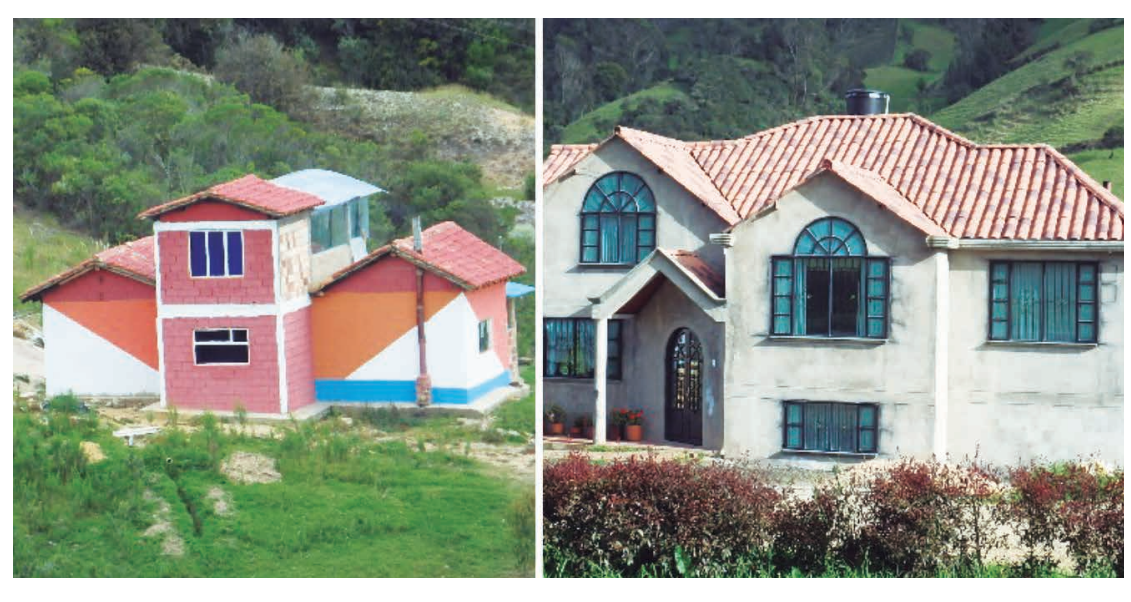

Figura 9. Viviendas rurales: Cómbita y Ventaquemada. Estéticas "erróneas". Fuente: autor.

Igualmente, se ha producido un cambio social. Commuters con hábitos urbanitas se han trasladado al entorno rural en las cercanías de Tunja (Chivatá, Oicatá, Motavita); Sogamoso y Duitama (Tibasosa). Allí buscan residir con una mejor calidad de vida y evitar los problemas causados por el crecimiento desordenado de estas ciudades. En cuestión de vivienda han adoptado el modelo tradicional, adaptando sus casas a la estética rural con mejoras técnicas y mayor confort. 

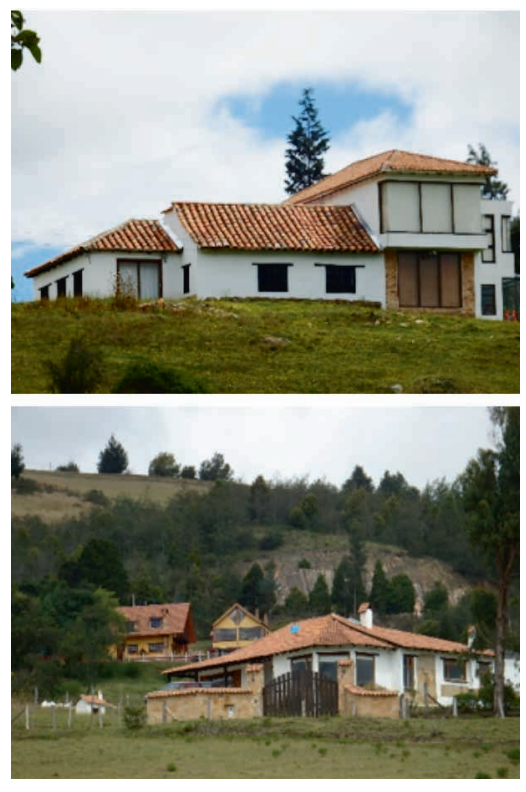

Figura 10. Viviendas de conmuters en Oicatá y Cómbita. Fuente: autor.

Como conclusión de esta fase valorativa, existe una pérdida acelerada y acusada, una alteración y un abandono de los elementos constitutivos del paisaje de minifundio boyacense. Dos son las causas fundamentales de tal situación: la emigración y la homogeneización resultante de la slobalización, ya sea de comportamientos, formas de vida, gustos, consumos y alimentación. Tal fenómeno conlleva a la sustitución de técnicas, utensilios y relaciones tradicionales por una fabricación en serie, estéticas desacertadas e imitación de estilos foráneos.

\section{Gestión del paisaje de minifundio}

La premisa esencial para la gestión del paisaje como bien y objeto patrimonial es la del Desarrollo Sostenible. Este, según la Comisión Brundlandt de la Organización de las Naciones Unidas (ONU, 1987) es aquel capaz de satisfacer las necesidades actuales sin comprometer los recursos y las posibilidades de las futuras generaciones.

Es el que puede mantenerse en el tiempo y se basa en cuatro pilares: debe ser económicamente rentable; redundar en beneficio de la sociedad; garantizar la protección del medio ambiente; y elevar el nivel cultural de la sociedad.

La fase de gestión ha de conducir a la intervención sobre el paisaje. El desarrollo sostenible no será una utopía vacua, sino una búsqueda a través de acciones tangibles en la producción, la sociedad y el conjunto del territorio. A continuación se presentan las propuestas que deben acometerse, desglosadas en términos de producción, hábitat y desde la perspectiva del paisaje mismo.

\section{BÚSQUEDA DEL DESARROLLO SOSTENIBLE (hábitat)}

\section{Mejora de las viviendas tradicionales.}

Recuperación de las técnicas constructivas ancestrales, más sostenibles y sismorresistentes.

Innovaciones técnicas (cimientos hidrófugos, mantenimiento con pañetados de barro, acristalamiento doble, adobes con secado a la sombra y con fibras vegetales).

Mejoramiento de caminos, accesibilidad.

Recuperación de linderos naturales.

\section{BÚSQUEDA DEL DESARROLLO SOSTENIBLE (producción)}

Reforma agraria y cooperativismo agrario.

Empoderamiento del género femenino.

Diversificación cultivos y productos (mermeladas, medicinas naturales, pigmentos, cosmética, alimentos deshidratados, de calidad, cadenas comerciales, mercadeo, denominaciones de origen). Nuevas formas de cultivo.

Búsqueda de cultivos tradicionales (Tubérculos andinos como la ibia, la ruba y el cubio).

Productos de calidad y denominación de origen.

Reforestación en laderas (nitrificación) con aliso, roble, encenillo.

Recuperación del patrimonio etnobotánico.

Minimizar los problemas ambientales de los pesticidas y monocultivos.

Apoyo a producción artesanal.

Incentivo para infraestructuras de alcantarillado, acueducto, vías de comunicación.

Energías alternativas (solar y eólica).

\section{BUSQUEDA DEL DESARROLLO SOSTENIBLE (paisaje)}

Recuperación paisajística de linderos, caminos, bosques, viviendas, cultivos, jardines criollos. Senderos etnobotánicos, naturalistas, miradores.

Desarrollo turismo ecológico y rural.

Tabla 4. Búsqueda del desarrollo sostenible (hábitat, producción y paisaje) Fuente: autor 


\section{CONCLUSIONES}

Las conclusiones son variadas, según la atención se centre en el método empleado o en el área de estudio. Respecto a lo último, las conclusiones de la investigación aparecen incorporadas en las fases descritas, pues los resultados del análisis se expresan a lo largo de la valoración y la gestión. Al ser un método propositivo, lo concluido explica una serie de indicaciones y propuestas orientadas a elevar el nivel de vida del campesinado y generarle un sentido de pertenencia por ese patrimonio que le representa, de modo tal que este actúe como catalizador de la recuperación, el mantenimiento y la mejora del paisaje.
En relación con el método, las tres fases del LAC aplicadas a una asociación de tipos de paisajes - la escala más grande que se puede analizar - es un ejemplo de uso y modelización de un marco para la transformación del territorio y la sociedad rural en conflicto en Boyacá. Para detallar áreas y tipos más puntuales, se trabajará en formas particulares y se incidirá directamente en las variaciones de los paisajes.

El LAC ha mostrado su adaptabilidad a cualquier lugar del mundo y escala, con sus posibilidades de fractalidad, integración y síntesis. Los estudios con este método amalgaman elementos históricos pasados y presentes, al tiempo que posibilitan la formulación de propuestas para el futuro. Los elementos analizados y valorados son de carácter físico, social y económico, lo cual permite superar la fractura entre lo natural y lo humano, recurrente en los análisis del paisaje y el patrimonio.

Las conclusiones respecto al paisaje como recurso patrimonial y generador de desarrollo sostenible indican que el minifundio boyacense está en peligro. Esto es así a pesar de la permanencia de microparcelas, pues estas carecen de gran valor agronómico en cuanto a cultivos potenciales, accesibilidad, productividad y reforma agrícola. A esto se suma el acelerado despoblamiento, fenómeno que "fosilizará" tal estructura de la tierra. Ciertamente hay una alteración respecto a la forma de estas áreas de montaña, pues se están perdiendo los linderos tradicionales de tapia pisada o árboles paravientos, los caminos, las especies autóctonas y la vivienda rural de adobe o tapia, ecológica, sismorresistente, termoestable y adaptada al rudo clima de altura, la cual experimenta además modificaciones por estéticas urbanas y materiales no tradicionales ni locales que destruyen o desvirtúan el valor del paisaje.

Esta alteración y destrucción del paisaje, aparte de ser estéticamente cuestionable, altera la calidad de vida de las personas del ámbito rural, ya que sus viviendas, bajo la aureola de "la modernidad", no se adaptan a las condiciones climáticas y 
ambientales. Asimismo, la ausencia de materiales autóctonos lleva a la pérdida de la relación con el entorno natural rural y causa un impacto en el medio. Se diluye así un recurso patrimonial que podría favorecer el desarrollo sostenible y ser una potencial fuente de turismo rural, cultural o agroturismo.

El minifundio rural boyacense se está perdiendo y desnaturalizando al no existir políticas claras de preservación de los elementos que lo diferencian, como tampoco criterios ni voluntad para mantenerlo, tanto por parte de la sociedad como de las autoridades. Esto ha ocasionado un desarraigo entre el patrimonio y la población, es decir, quienes habitan el territorio no se sienten identificados con sus bienes culturales y naturales. Esta falta de valoración y de reconocimiento puede desembocar en la desaparición de este tipo de paisaje.

Se necesitan políticas específicas para la recuperación de los valores de identidad de este paisaje. Las medidas requeridas no solo deben incidir en el patrimonio inmueble, sino también en lo económico, social, cultural y educativo, de manera que impliquen nuevas oportunidades para los habitantes de estos territorios.

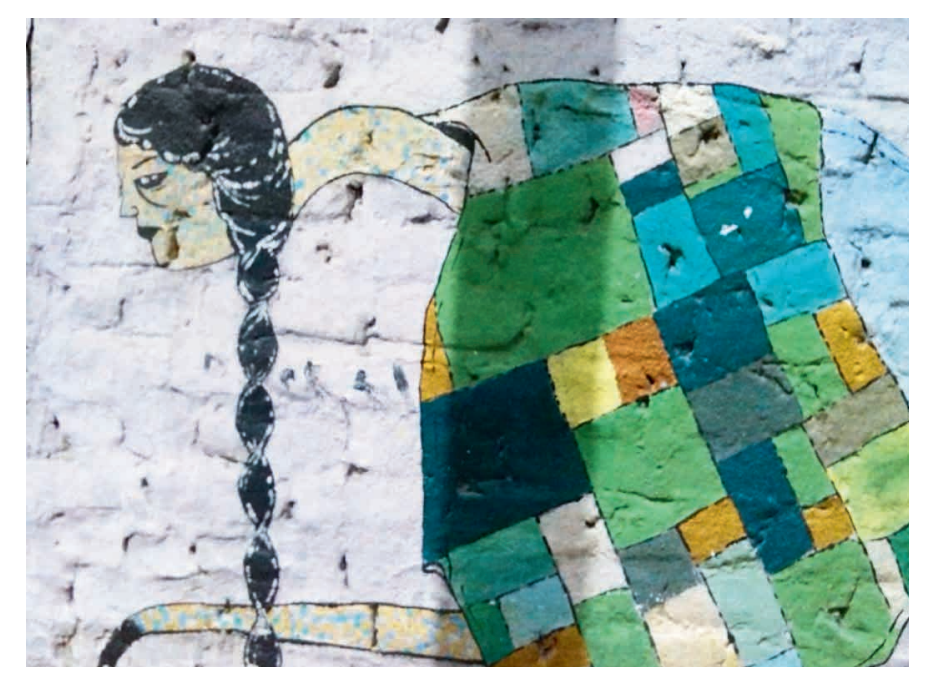

Figura 10. Pintura de un muro de Tunja representando a una mujer indígena con la manta muisca en parches, como si fuera la madre Tierra. Fuente: autor. 
Bertrand, G. (2010). Itinerario en torno al paisaje: una epistemología de terreno para tiempos de crisis. Eria, 81, 5-38.

Castellanos Camacho, L. I. (2011). Conocimiento etnobotánico, patrones de uso y manejo de plantas útiles en la cuenca del río Cane-Iguaque (Boyacá, Colombia): una aproximación desde los sistemas de uso de la biodiversidad. Rev. Ambiente y Sociedad, 14(1), 45-75.

Consejo de Europa. (2000). Convenio Europeo del Paisaje. Recuperado de http:// www.magrama.sob.es/en/desarrollo-rural/temas/desarrollo-territorial/convenio. aspx

González Bernáldez, A. (1981). Ecología y Paisaje. Madrid: Blume.

DANE (2013). Boletín de pobreza en Boyacá 2013. Recuperado de https:// www.dane.gov.co/files/investigaciones/condiciones_vida/pobreza/Boyaca_Pobreza_2013.pdf

Luginbuhl, Y. (1991). Le paysage rural: la couleur de l'agricole, la saveur de l'agricole, mais que reste-t-il de l'agricole. Études rurales, (121-124), 27-44.

Mata Olmo, R. (2008). El paisaje, patrimonio y recursos para el desarrollo territorial sostenible, conocimiento y acción pública. Arbor: Ciencia, Pensamiento y Cultura, 184(729), 155-172.

Melo, J. O. (2007). ¿Cuánta tierra necesita un indio? Recuperado de http:// www.jorgeorlandomelo.com 
Ministerio de Agricultura y Desarrollo Rural de Colombia. (2005). Censo de Microfundio en Colombia. Bogotá: autor.

ONU. (1987). Informe de la Comisión sobre Medio Ambiente y DesarroIlo (Informe Brundlandt). Recuperado de http://www.un.org/es/comun/ docs/?symbol $=\mathrm{A} / 42 / 427$

Orozco Farfán, B. R. \& Rojas Otero, E. (2000). Vivienda rural y medio ambiente. Recuperado de http://lunazul.ucaldas.edu.co/downloads/Lunazul9_10_6.pdf

Pardo de Santayana, M. \& Gómez, E. (2003). Etnobotánica: aprovechamiento tradicional de plantas y patrimonio cultural. Anales del Jardín Botánico de Madrid, 60(1), 171-182. Recuperado de: http://dialnet.unirioja.es/servlet/ articulo? codigo $=30673$

Saldarriaga, A. (Ed.). (2009). Pasados presentes. La vivienda en Colombia. Bogotá: Pontificia Universidad Javeriana.

UNESCO. (2008). Directrices operativas para la aplicación de la Convención del Patrimonio Mundial. Recuperado de http://whc.unesco.org/archive/opguide08-es.pdf

UNESCO. (1992). Paisajes Culturales. Recuperado de http://whc.unesco.org/en/ culturallandscape/

Vélez Álvarez, L. G. (2012). Política y legislación de tierras en Colombia en los siglos XIX y XX. Documento de Economía y finanzas, (12-29). Bogotá. EAFIT. 